\title{
Inattentional Blindness During Driving in Younger and Older Adults
}

\author{
Raheleh Saryazdi1,2, Katherine Bak ${ }^{1}$ and Jennifer L. Campos ${ }^{1,2 *}$ \\ ${ }^{1}$ Toronto Rehabilitation Institute, University Health Network, Toronto, ON, Canada, ${ }^{2}$ Department of Psychology, University \\ of Toronto, Toronto, ON, Canada
}

Age-related changes to perceptual and cognitive abilities have been implicated in an increased risk of collision in older adults. This may be due, in part, to their reduced ability to attend to potentially relevant aspects of their driving environment. An associated general phenomenon of inattentional blindness involves a failure to notice visually presented objects or events when attention is directed elsewhere. Previous studies of inattentional blindness using computer paradigms report higher incidence of this effect in older compared to younger adults. However, little is known about whether these age-related effects are observed during more complex, realistic, everyday tasks, such as driving. Therefore, the goal of this study was to explore whether younger and older adults differ in their awareness of objects in their driving environment when their attention is directed toward another primary driving task. This study took place in a high-

OPEN ACCESS

Edited by:

Annalisa Setti

University College Cork, Ireland

Reviewed by:

Ciara Greene,

University College Dublin, Ireland

David lan Anderson,

San Francisco State University,

United States

*Correspondence:

Jennifer L. Campos

jennifer.campos@uhn.ca

Specialty section:

This article was submitted to

Performance Science,

a section of the journal

Frontiers in Psychology

Received: 21 December 2018

Accepted: 03 April 2019

Published: 26 April 2019

Citation:

Saryazdi R, Bak K and Campos JL (2019) Inattentional Blindness During

Driving in Younger and Older Adults.

Front. Psychol. 10:880.

doi: 10.3389/fpsyg.2019.00880 fidelity, full field of view, driving simulator. Thirty-two younger $\left(M_{\text {age }}=25.41\right)$ and 32 older ( $\left.M_{\text {age }}=73.41\right)$ adults drove through 19 short scenarios and were asked to first judge whether their vehicle could fit between two rows of vehicles parked on either side of the road and then to perform the associated driving maneuver (i.e., drive through or drive around). On four critical trials, objects were placed on the side of the road that differed in terms of animacy. Specifically, animate objects consisted of 3D humans standing by a bus shelter and inanimate objects consisted of photographs of the same individuals on a bus shelter advertisement. Inattentional blindness was measured via a post-drive, tabletbased recognition task immediately following the critical trials. Results revealed high rates of inattentional blindness across both age groups, with significantly lower levels of awareness for inanimate objects compared to animate objects. Further, whereas younger adults demonstrated reduced inattentional blindness following the first critical trial, older adults did not show this immediate improvement in recognition performance. Overall, this study provides unique insights into the factors associated with age-related changes to attention and how they may affect important driving-related outcomes.

Keywords: attention, aging, simulator, awareness, hazard, perceptual, cognitive, load

\section{INTRODUCTION}

For many older adults, driving provides a sense of autonomy, contributes to community mobility, and helps to maintain overall quality of life. However, older adults are among the most vulnerable to traffic-related injuries and death caused by vehicle collisions (Transport Canada, 2014; Jackson and Cracknell, 2018). A recent systematic review by Vichitvanichphong et al. (2015) indicated that the 
most frequent driving errors made by older adults are those related to lane control, decision making, recognizing and responding to signs, visual scanning, and physical control of the vehicle. Older drivers are also particularly vulnerable to collisions during conditions of high sensory, perceptual, and cognitive load (e.g., when making left turns at intersections; Cantin et al., 2009; Road Safety Canada, 2011; Vichitvanichphong et al., 2015). These types of driving errors and increased collision rates are likely attributable to a variety of age-related changes, including but not limited to changes in sensory abilities (e.g., visual acuity, contrast sensitivity), perceptual abilities (e.g., time to contact estimation), and cognitive abilities (e.g., selective attention and working memory). Ultimately, the implications of these age-related effects on driving performance could include a reduced ability for older drivers to detect and/or interpret potential driving hazards, particularly when their perceptual and/or cognitive resources are taxed. Therefore, the goal of this study was to explore whether younger and older adults differ in terms of their awareness of objects in their driving environment when their attention is directed toward a primary driving task.

\section{Inattentional Blindness, Perceptual, and Cognitive Load During Driving}

The failure to notice an object or event when attention is directed toward a primary task or target is referred to as "inattentional blindness" (Mack and Rock, 1998). In a classic study demonstrating this effect, observers who were shown a video of a basketball game and asked to count the number of ball passes, often failed to notice a gorilla that walked purposely across the basketball court (Simons and Chabris, 1999). The extent to which inattentional blindness is observed can depend on several factors including the primary task demands, the nature of the unexpected object/feature, and the characteristics of the observer themselves (Kreitz et al., 2016). In terms of individual characteristics, a number of studies have shown the rate of inattentional blindness to vary as a function of age. For example, Graham and Burke (2011) replicated the Simons and Chabris (1999) study with younger and older adults and revealed that older adults were even more susceptible than younger adults to inattentional blindness in this task (i.e., much less likely to notice the gorilla). Other studies have replicated this increased susceptibility of older adults to exhibit inattentional blindness using a variety of computer-based paradigms (e.g., Stothart et al., 2015, 2016; Horwood and Beanland, 2016). Very little, however, has been explored with regards to whether age-related differences in inattentional blindness are also observed during complex and realistic everyday tasks such as driving.

During multisensory, multitasking activities such as driving, the ability to attend to objects in the environment that are not immediately relevant to the task itself can be particularly challenging. As such, broad object awareness may generally be limited during driving compared to less complex tasks, particularly during conditions of higher cognitive and perceptual load. For instance, cognitive load can be increased during driving by the introduction of multitasking requirements (e.g., listening/talking, holding information in memory, navigating; Strayer and Johnston, 2001; Strayer et al., 2003, 2013; Horrey and Wickens, 2006; Blalock et al., 2014; Cuenen et al., 2015; Donmez and Liu, 2015; Ebnali et al., 2016; Svetina, 2016; Murphy and Greene, 2017a; Caird et al., 2018; Wechsler et al., 2018) and perceptual load may be introduced by, for example, environmental clutter (e.g., traffic, buildings, signs, pedestrians; Marciano and Yeshurun, 2012, 2015; Stinchcombe and Gagnon, 2013; Ericson et al., 2017; Michaels et al., 2017), or by increasing perceptual task difficulty (e.g., judging maneuverability around closely arranged obstacles; Murphy and Greene, 2015, 2016). Previous studies with younger drivers have demonstrated more instances of inattentional blindness during conditions of higher compared to lower cognitive and perceptual load (e.g., Most and Astur, 2007; Blalock et al., 2014; Murphy and Greene, 2015, 2016, 2017a,b; Ericson et al., 2017; see Murphy et al., 2016 for a review). For instance, Murphy and Greene (2015, 2016) investigated the effects of perceptual load on inattentional blindness by asking drivers to make perceptual gap judgements about whether their car could fit between a row of parked cars while manipulating perceptual difficulty (i.e., clearly too wide/narrow vs. closely approximating the width of the driver's vehicle). Their results demonstrated greater rates of inattentional blindness to roadside objects during the higher load conditions compared to the lower load conditions.

Importantly, very little is understood about how perceptual load affects inattentional blindness in older adults. Because there are well-documented age-related changes to, for instance, attentional capacity (Craik and McDowd, 1987; McDowd and Craik, 1988) and inhibitory control of attention (Hasher and Zacks, 1988; Lustig et al., 2007), it may be expected that older adults would demonstrate differences in inattentional blindness under load compared to younger adults (Graham and Burke, 2011). For instance, the attentional capacity model of cognitive aging posits that older adults have a more limited attentional capacity than do younger adults (Craik and McDowd, 1987; McDowd and Craik, 1988). As such, older adults might be less likely to detect an object that is not relevant to the primary driving task and hence may be more susceptible to inattentional blindness (e.g., Graham and Burke, 2011; Horwood and Beanland, 2016). Other theories of age-related changes in attention posit that older adults are less able to inhibit their awareness of information that is irrelevant to their primary task (Hasher and Zacks, 1988), suggesting that they may have increased awareness of environmental objects/features and thus, may be less susceptible to inattentional blindness. Although past studies of inattentional blindness provide support for the predictions made by the attentional capacity model (e.g., Graham and Burke, 2011; Horwood and Beanland, 2016; Liu, 2018), less is understood about the role of perceptual/cognitive load on these effects, or the role of different object characteristics. It is possible, for instance, that under different primary task loads, when using different measures of awareness, and/or with different degrees of object relevance, these age-related differences in inattentional blindness may vary (Michaels et al., 2017). Driving experience is another important consideration as older adults typically have accumulated more years of driving than younger adults, which in turn could compensate for their age-related functional declines. 
However, previous studies examining years of driving experience have revealed little to no effect on various driving measures (e.g., Shinar et al., 2005; Kass et al., 2007; Smahel et al., 2008) and very little is understood about the effects of lifetime driving experience on attention during driving.

\section{Effects of Object Type: Role of Animacy}

Objects that are more salient and/or more relevant to the primary task may receive greater levels of awareness. One object feature that has been shown previously to affect rates of inattentional blindness is animacy. Specifically, past studies using simple computer-based tasks with static stimuli have reported lower rates of inattentional blindness for animate (e.g., animals/humans) compared to inanimate stimuli (e.g., tools/transportation vehicles; Calvillo and Jackson, 2014; Calvillo and Hawkins, 2016). In the context of driving, the characteristic of animacy is particularly important because it determines whether the object could, at any moment, become relevant to the primary driving task (i.e., the need to initiate a reactive response to things that can move). A driver should be prepared to avoid an animate object that has the potential to enter the roadway, whereas a stable, inanimate roadside object would be less of a concern. A study by Pammer et al. (2015), in which participants were presented with photographs of driving scenes, revealed a reduction in the rate of inattentional blindness as the threat of a hazard increased (e.g., a child on the side of the road compared to an adult). What is not clear is whether these effects would be observed during dynamic driving tasks, and/or under conditions of higher load. Assuming there are limited attentional resources, the awareness of some objects (e.g., animate) may be prioritized over others. However, it is also possible that once the driving load (perceptual and/or cognitive load) becomes too great, the effects of animacy are diminished. What is also not yet known is whether older adults' awareness is differentially affected by animacy compared to younger adults'. For instance, age-related reductions of inhibitory control could be advantageous when an object is potentially relevant (animate) and leads to the detection of a hazard to be avoided, whereas it could be disadvantageous if the object is irrelevant (inanimate) and directs attention away from the primary task of driving. Therefore, the objectives of the current study were to evaluate inattentional blindness in younger and older adults, both in terms of animate and inanimate roadside objects during an active driving simulator task. Specifically, the animate objects consisted of $3 \mathrm{D}$ humans standing by a bus shelter and the inanimate objects were photographs of the same individuals on the bus shelter advertisement. To introduce load during driving, a gap judgment task (similar to Murphy and Greene, 2015, 2016) was implemented whereby the participants' primary task was to determine whether they could drive between two rows of parked vehicles or whether they had to drive around (and then execute the associated maneuver). The primary goal of the gap judgment task was to introduce a sufficiently attention-demanding secondary task and was not intended as a manipulation to evaluate the specific effects of high versus low perceptual and/or cognitive load. The rate of inattentional blindness was measured via a post-drive, tablet-based recognition task immediately following the critical trials.

\section{MATERIALS AND METHODS}

\section{Participants}

Seventy-one participants were recruited through advertisements posted in the local Toronto community. Due to simulator sickness, seven of the participants ( 5 older adults and 2 younger adults) were not able to complete the experimental task and were therefore excluded from the study. The final sample included 32 healthy younger adults (Age range $=20-35, M=25.41$, $S D=4.58$, Male $=16$ ) and 32 healthy older adults (Age range $=65-90, M=73.41, S D=6.19$, Male $=18$ ). All participants completed a pre-screening questionnaire to ensure that they met the eligibility criteria, namely age (younger adults 20-35; older adults $65+$ ), and having a valid driver's license, 2 years of recent driving experience, normal or corrected-to-normal visual acuity (verified with in person screening - see below), and no history of serious physical, neurological, or psychological disorders. Individuals who were eligible were invited to participate in the experimental session and were compensated \$10 per hour for their participation. The protocol for the present study was approved by the University Health Network's Research Ethics Board (REB 17-5596).

\section{Demographics, Sensory, and Cognitive Measures}

Participants were administered a series of assessments in person, including a health history and demographics questionnaire, driving habits questionnaire (Owsley et al., 1999), and motion sickness susceptibility questionnaire (Golding, 2006). Visual acuity was assessed using the Early Treatment Diabetic Retinopathy Study visual distance test (ETDRS; Ferris et al., 1982) and -0.2 to $0.5 \log$ Mar units was considered as the acceptable range for the normal to near-normal visual acuity cutoff (International Council of Ophthalmology, 2002). In order to characterize the cognitive abilities of younger and older adults, a series of standardized cognitive tests were administered. The WAIS-III forward and backward digit span (Wechsler, 1997) was administered as a measure of working memory, with lower scores indicating poorer performance. For all of the remaining cognitive measures described below, a lower score indicates better performance. The Stroop test (Stroop, 1935) was used as a measure of inhibition and was scored by subtracting the number of correct words uttered per second in the neutral condition (colored asterisks) from the incongruent condition (word-color match/mismatch). The Trail Making Tests A and B (Reitan, 1955) were used as a measure of executive function with the score calculated as the completion time difference between the two versions (B minus A). In addition, we administered the Useful Field of View Test (UFoV; Ball and Owsley, 1993), a computerized task in which participants must identify a central object and the location of a peripheral object in the presence/absence of distractors. This task computes subscores for selective attention, divided attention, processing speed, 


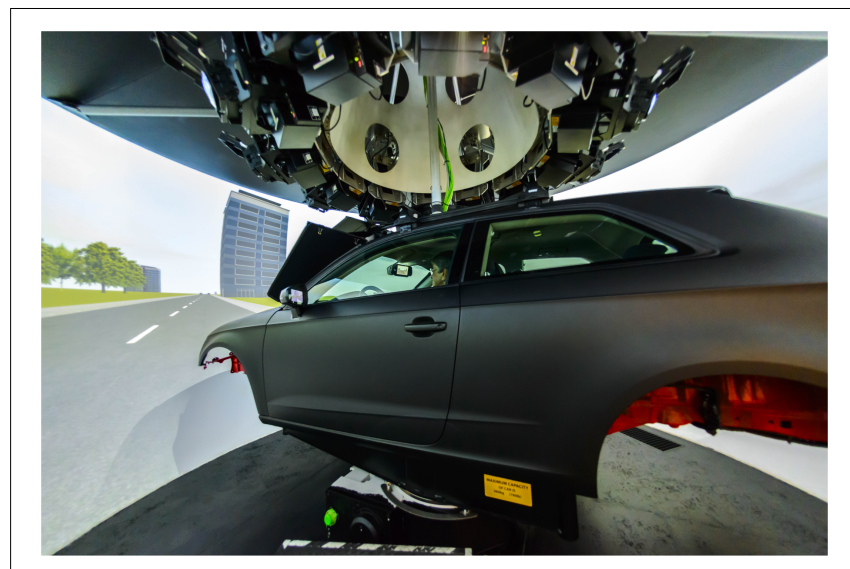

FIGURE 1 | DriverLab at the Toronto Rehabilitation Institute - University Health Network (written informed consent was obtained from the depicted individuals for the publication of this image).

as well as a total composite score, and is considered to be a strong predictor of driving collision frequency in older adults (Ball and Owsley, 1993). Finally, all older adults were administered the Montreal Cognitive Assessment (MoCA; Nasreddine et al., 2005) to screen for mild cognitive impairment. Due to technical error, we were not able to compute scores for one older adult for the digit span, three younger adults for the Stroop, and one younger adult for Trails A and B.

\section{Stimuli and Apparatus \\ Driving Simulator}

The study took place at the Toronto Rehabilitation Institute's Challenging Environment Assessment Laboratory and used DriverLab, a state-of-the-art driving simulator (Figure 1). DriverLab is equipped with a full-sized passenger vehicle (Audi A3) containing all of its original internal components (e.g., steering wheel, gas/brake pedals, seats, and dashboards). The vehicle is completely surrounded by a 360-degree field of view visual projection system (12 Eyevis ESP-LWXT-2120, $1920 \times 1200 ; 120 \mathrm{~Hz}$ projectors $)$ and has vehicle-integrated surround sound (Pioneer VSX-45 Receiver, 5.1 sound; JL Audio powered sub and Focal speakers).

\section{Driving Scene/Scenario}

The driving scenes/scenarios were developed and presented using Oktal SCANeR Studio version 1.7 and MATLAB R2015b (The MathWorks Inc., 2015). The driving scenarios consisted of a straight rural road with no active traffic (see Figure 2). The number of objects in the scenarios (e.g., buildings and trees) was kept minimal and was balanced on both sides of the road. The entire road was approximately $1,000 \mathrm{~m}$ long. At approximately $820 \mathrm{~m}$ from the start of the drive, two rows of three vehicles were parked on either side of the road. The range of distances between the two rows of parked vehicles was 2.05-2.75 m apart. A bus shelter was positioned $14 \mathrm{~m}$ before the rows of parked vehicles on the right hand side of the road.

\section{Target and Distractor Stimuli}

The target objects within the driving scene and the target and distracter objects that were presented via the tablet during the post-drive recognition task were created using Google SketchUp, version 17.2.2 and the Google 3D warehouse. Target objects presented during critical driving trials were either animate or inanimate. Animacy was manipulated by presenting either a $3 \mathrm{D}$ person standing in the bus shelter (animate), or the same person depicted on a full height advertisement in the bus shelter (inanimate). Specifically, we included four people for the critical trials (2 males, 2 females depicted as either animate or inanimate) and four different people in filler trials (2 males, 2 females depicted as either animate or inanimate). In order to control for other non-animacy related differences between the two different animacy trial types, the advertisement content present in the inanimate trials was also replicated within the bus shelter during animate trials (i.e., in the animate trials, the same advertisement without the person was positioned directly behind the $3 \mathrm{D}$ person). This resulted in manipulating animacy while controlling for the general visual content in both the animate and inanimate trials (see Figure 3). Note that although the size of the person in the inanimate is smaller than the animate person, it is still quite large and clearly visible (e.g., the height of the inanimate man in the suit on Figure 3 is $1.5 \mathrm{~m}$ ).

\section{Tablet-Based Response Measures}

Additional sets of 3D images were obtained and converted to $2 \mathrm{D}$ graphics for the four trials involving the tablet test of inattentional blindness. Importantly, each of these trials included

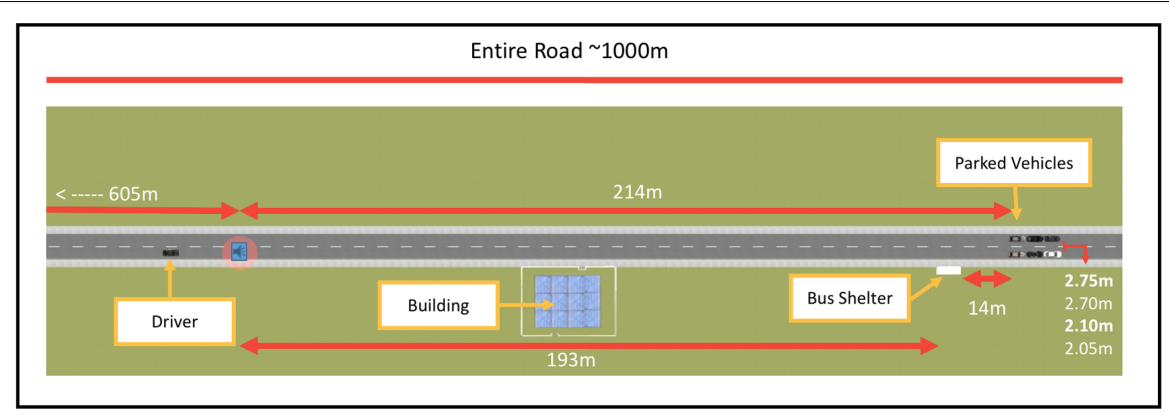

FIGURE 2 | A top-down view of the driving scenario. 


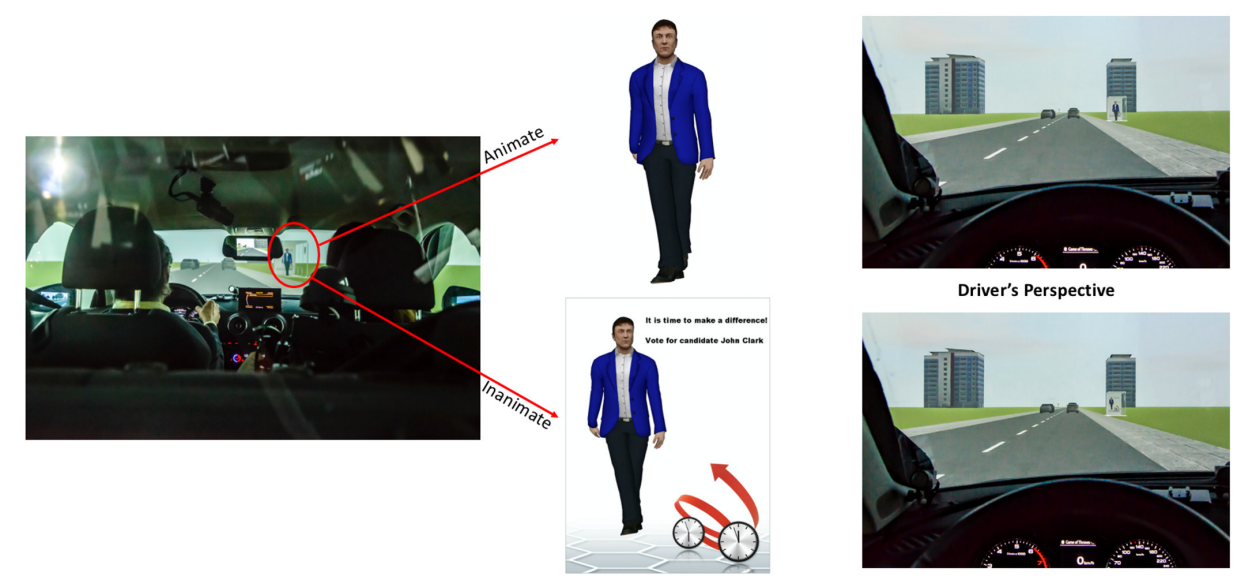

FIGURE 3 | Example stimuli including animate (top) and inanimate (bottom) objects (written informed consent was obtained from the depicted individuals for the publication of this image).

two human characters; one who was present in the driving scene (critical target) and one who was not (competitor), as well as two plausible, non-human roadside objects (e.g., bicycle, mailbox, and newspaper stand), none of which ever appeared in the driving scene. These four images were presented on a $10^{\prime \prime}$ Samsung Galaxy tablet. Each image was depicted on a white background at a $220 \times 260$ pixel resolution and the image location of each object type (within the four quadrants) was randomized across trials. Although the critical target and the human competitor for each trial matched in terms of their sex, they differed in terms of other characteristics (e.g., posture, clothing, and hairstyle), which provided additional unique identifiers apart from just different facial features across targets/competitors. This is an important detail, given that previous literature has suggested that face stimuli are unique in that they are processed to a greater degree than non-face stimuli under higher load conditions (Lavie et al., 2003).

\section{PROCEDURE}

After providing informed written consent, participants were asked to complete the set of questionnaires mentioned earlier. They were then guided to DriverLab and were assisted in adjusting their seat and getting familiarized with the vehicle. During the entire driving session, which lasted approximately $30 \mathrm{~min}$, one researcher always sat in the passenger seat of the car with the participant, and another researcher monitored the experiment from outside the simulator.

\section{Familiarization Phase}

Participants were first required to complete a $5 \mathrm{~min}$ familiarization phase, which involved driving along a straight rural road that was similar in nature, but not identical to the main experimental scenarios. During this phase, participants were asked to maintain a speed of $80 \mathrm{~km} / \mathrm{h}(\sim 50 \mathrm{miles} / \mathrm{h})$, make several lane changes, and drive on the shoulder. Participants were instructed to obey all traffic rules as they completed the driving task (e.g., obey speed limits, use their indicator before changing lanes, and avoid obstacles). Upon completion of the familiarization phase, participants were asked to report any symptoms of motion sickness and confirm that they were comfortable with proceeding to the experimental phase.

\section{Experimental Phase}

Participants were instructed to drive along a straight, one-way rural road in a series of short driving trials. They started from a parked position on the road and drove straight forward within the right-hand lane. It was explained to them that they would come across a section of the road with vehicles parked on either side of the road and, upon approaching these vehicles, they would have to make a gap judgment to determine whether they could fit between the vehicles or whether they would need to navigate around the vehicles by driving on the shoulder. They were assured that the driving simulator car's physics had been turned off so they would not feel any physical impact if they made an error in the gap judgment. Gap values were either "plausible" to drive through (Wide: $2.75 \mathrm{~m}, 2.70 \mathrm{~m}$ ) or "implausible" to drive through (Narrow: $2.10 \mathrm{~m}, 2.05 \mathrm{~m}$ ) with respect to "fit-ability". The width of the driver's vehicle was $1.8 \mathrm{~m}$ and although physically they could drive through the narrow gap, it would have been difficult and perceived as potentially "dangerous" to do so.

At a defined decision point before reaching the parked vehicles (marked by an auditory tone, see red circle and sound icon on Figure 2), participants were instructed to signal left if they believed that they could drive through the parked vehicles and signal right if they believed that they had to drive around the parked vehicles. Importantly, they were asked to follow their signal by performing the associated driving maneuver. Participants were also told to maintain the same speed as during the practice phase $(80 \mathrm{~km} / \mathrm{h})$ and to bring the car to a stop at their own comfortable pace after driving through/around the parked vehicles. After confirming that participants understood the instructions, they were informed that they could not converse with the experimenter while driving. 
The experimental phase involved 19 short driving scenarios ( 2 practice +16 experimental +1 probe trial). The four different gap sizes were equally represented across the 16 experimental trials and the two practice trials included one narrow $(2.05 \mathrm{~m})$ and one wide gap $(2.75 \mathrm{~m})$. Across the 16 experimental trials there were also four instances of each of the following object conditions: bus shelter with an animate object (3D person), bus shelter with an inanimate object (advertisement), an empty bus shelter, and no bus shelter. The two practice trials had empty bus shelters. Across the experimental trials, these object conditions were equally divided among the gap conditions. The pairing of conditions was accomplished using a list design, varying whether a wide or narrow gap size accompanied an animate or an inanimate roadside object. Although all participants were presented with all four combinations across the four critical trials, they were only presented with a particular object once. For example, each participant would be presented with the man in the suit depicted in Figure 3 only in one of the four critical trial combinations: (1) animate and narrower gap; (2) inanimate and narrower gap; (3) animate and wider gap; (4) inanimate and wider gap. The same character was associated with the same critical trial across participants (e.g., the man in the suit in Figure 3 was always the first critical trial). Moreover, to ensure that the participants could, in fact, perceive the roadside object when their attention was not divided by the gap judgment task, we also included a probe trial at the end of all experimental trials, in which participants were presented with a bus shelter that contained an object (an animate or inanimate man) but they did not have to make a gap judgment (i.e., there were no parked vehicles on the road). All participants did in fact see the roadside object (performance was at $100 \%$ for both animate and inanimate probe trials) and thus no further exclusions were required.

On four of the 16 experimental trials, inattentional blindness was assessed using a forced-choice recognition task presented on a tablet immediately after the driving trial. Specifically, participants were asked to select an image of the object that they recognized from the preceding trial. Each trial was coded for accuracy (correct/incorrect) and incorrect trials were further coded for same category error (choosing the human competitor) versus different category error (choosing a non-human object). Upon the completion of the experimental task, participants were asked to rate their level of simulator sickness on a scale of 0 (no sickness) to 20 (extreme sickness, Keshavarz and Hecht, 2011). Both younger and older adults reported low and similar rates of sickness $(M=2.31, M=2.02$, respectively). Finally, participants were asked to complete the remaining set of cognitive performance measures. Overall, the study took approximately $1.5-2 \mathrm{~h}$ to complete. Considering the possibility that time of the day could differentially affect younger and older adults' performance (Anderson et al., 2014), we balanced the time of testing for each age group by having approximately the same number of younger and older adults tested in the morning and afternoon sessions.

\section{Data Analyses}

All statistical analyses were conducted using $\mathrm{R}$ Version 3.3.3 ( $\mathrm{R}$ Core Team, 2017). The comparisons of younger and
TABLE 1 | Participant demographics and baseline measures.

\begin{tabular}{|c|c|c|c|}
\hline & Younger adults $(N=32)$ & Older adults $(N=32)$ & \\
\hline & $M(S D)$ & $M(S D)$ & $p$-value \\
\hline \multicolumn{4}{|l|}{ Demographics } \\
\hline Age (years) & $25.41(4.58)$ & $73.41(6.19)$ & $<0.001^{*}$ \\
\hline Education (years) & $17.19(2.28)$ & $18.25(3.44)$ & 0.151 \\
\hline \multicolumn{4}{|l|}{ Vision } \\
\hline ETDRS left eye ${ }^{1}$ & $0.06(0.18)$ & $0.19(0.16)$ & $0.003^{*}$ \\
\hline ETDRS right eye $^{1}$ & $0.03(0.17)$ & $0.18(0.14)$ & $<0.001^{*}$ \\
\hline \multicolumn{4}{|l|}{ Cognition } \\
\hline $\mathrm{MoCA}^{2}$ & - & 26.09 (2.99) & - \\
\hline Digit span ${ }^{3}$ & $18.13(3.23)$ & $16.61(3.21)$ & 0.067 \\
\hline Stroop 4 & $0.56(0.19)$ & $0.47(0.18)$ & 0.077 \\
\hline Trails ${ }^{5}$ & $27.74(9.97)$ & $62.19(52.07)$ & $<0.001^{*}$ \\
\hline \multicolumn{4}{|l|}{ UFoV $^{6}$} \\
\hline Processing speed & $17.41(4.72)$ & $21.91(20.24)$ & 0.229 \\
\hline Divided attention & $18.41(7.46)$ & 70.03 (87.10) & $0.002 *$ \\
\hline Selective attention & $42.41(23.78)$ & 171.72 (96.49) & $<0.001^{*}$ \\
\hline Total score & $78.22(29.22)$ & 263.66 (164.22) & $<0.001^{*}$ \\
\hline
\end{tabular}

* Significance level of $p<0.05$ when comparing younger and older participant group scores; ' Early Treatment Diabetic Retinopathy study scores in logMAR units; ${ }^{2}$ Montreal Cognitive Assessment, adjusted for years of education; ${ }^{3}$ score out of 30; ${ }^{4}$ number of correct words per second from neutral condition to incongruent condition; ${ }^{5}$ Trails $B-A ;{ }^{6}$ Useful Field of View.

older adults' performance on baseline measures were analyzed with independent samples $t$-tests (see Table 1). All primary experimental dependent measures were analyzed using logistic mixed-effects analyses. These analyses were carried out using the lme4 package Version 1.1-15 (Bates et al., 2015) and lmerTest package Version 3.0-1 (Kuznetsova et al., 2017). Age (younger vs. older) was treated as a between-participants factor, and gap size (wide vs. narrow) and animacy (animate vs. inanimate) were treated as within-participant factors. The dependent measures were "accuracy" in gap judgment (accuracy here reflects driving through the parked vehicles when the gap was clearly wide enough and driving around the parked vehicles when the gap was too narrow to be considered safe to drive through) and accuracy in the rate of detection of the animate/inanimate object, which were both treated as binary outcomes (correct/incorrect). The random effects structure included a random intercept term for participant, a by-participant slope term for gap size in the analysis of gap judgment accuracy, and a by-participant slope term for animacy in the analysis of inattentional blindness. The results of these analyses are presented in Table 2.

\section{RESULTS}

\section{Demographic, Sensory and Cognitive Measures}

Both younger and older participants were similar in terms of demographic background, with most having completed, or were in the process of completing a university-level degree. To compare the driving habits of younger and older adult 
TABLE 2 | Summary of the results for mixed effect analyses.

\begin{tabular}{|c|c|c|c|c|}
\hline Effect & Estimate & SE & $\boldsymbol{Z}$ & $p$ \\
\hline \multicolumn{5}{|l|}{ Gap judgment accuracy } \\
\hline (Intercept) & 2.43 & 0.23 & 10.78 & $<0.001$ \\
\hline Gap size & -0.23 & 0.29 & -0.79 & 0.432 \\
\hline Age & 0.38 & 0.19 & 2.06 & 0.039 \\
\hline Gap size $\times$ age & -0.47 & 0.26 & -1.82 & 0.069 \\
\hline \multicolumn{5}{|l|}{ Inattentional blindness } \\
\hline (Intercept) & 0.59 & 0.25 & 2.36 & 0.018 \\
\hline Age & 0.35 & 0.23 & 1.56 & 0.119 \\
\hline Animacy & 0.83 & 0.21 & 3.99 & $<0.001$ \\
\hline Age $\times$ animacy & 0.29 & 0.18 & 1.55 & 0.121 \\
\hline \multicolumn{5}{|l|}{$\begin{array}{l}\text { Inattentional blindness } \\
\text { growth curve analysis }\end{array}$} \\
\hline (Intercept) & 0.75 & 0.25 & 3.00 & 0.003 \\
\hline Linear & -0.15 & 0.38 & -0.38 & 0.702 \\
\hline Quadratic & 0.52 & 0.42 & 1.24 & 0.216 \\
\hline Age & 0.43 & 0.25 & 1.72 & 0.086 \\
\hline Animacy & 0.95 & 0.21 & 4.58 & $<0.001$ \\
\hline Linear $\times$ age & 0.78 & 0.38 & 2.04 & 0.042 \\
\hline Quadratic $\times$ age & 0.68 & 0.42 & 1.62 & 0.105 \\
\hline Linear $\times$ animacy & 0.28 & 0.38 & 0.74 & 0.460 \\
\hline Quadratic $\times$ animacy & -0.30 & 0.50 & -0.61 & 0.545 \\
\hline Age $\times$ animacy & 0.30 & 0.21 & 1.47 & 0.142 \\
\hline Linear $\times$ age $\times$ animacy & 0.12 & 0.38 & 0.31 & 0.759 \\
\hline Quadratic $\times$ age $\times$ animacy & 0.21 & 0.50 & 0.43 & 0.669 \\
\hline
\end{tabular}

Contrast coding: age (younger adults $=1$, older adults $=-1$ ); perceptual gap judgment (narrow gap $=1$, wide gap $=-1$ ); animacy (animate $=1$, inanimate $=-1$ ).

participants, we compiled an average score from the information collected on the driving habits questionnaire, accounting for both the average number of trips driven and average distances traveled on a weekly basis. The two age groups were very similar in terms of the average kilometers driven per week (Younger Adults: $M=142.31 \mathrm{~km}, S D=186.79$; Older Adults: $M=131.48 \mathrm{~km}$, $S D=142.72$ ). Younger and older adults also did not differ in terms of their susceptibility to motion sickness.

Younger and older adults were also compared for each of the measures of sensory and cognitive functioning. Whereas younger adults had better visual acuity than older adults overall, both groups' average score of left and right eye acuity fell within the normal to near-normal range $(-0.2$ to $0.5 \log$ Mar units; International Council of Ophthalmology, 2002). In terms of the battery of cognitive measures, there were no significant group differences on the digit span test $(p=0.067)$ or the Stroop test $(p=0.077)$. However, younger adults performed significantly better than older adults on the Trail Making $(p<0.001)$ and the UFoV $(p<0.001)$ tests. Notably, the agerelated differences in UFoV were evident for measures of divided attention $(p=0.002)$ and selective attention $(p<0.001)$, but not processing speed $(p=0.229)$.

Nine older adults scored below the MoCA cut-off for mild cognitive impairment $(<26)$, however, these participants were still included in the analyses because their performance in the experimental task did not differ from their peers. To confirm and justify the inclusion of these individuals, a series of sensitivity analyses were conducted for all the primary measures of interest, which further revealed no significant effect of including versus excluding this group of participants. Therefore, all reported analyses are based on the full sample size of 32 younger and 32 older adults.

\section{Gap Judgment Accuracy}

The purpose of the gap judgment task was to introduce a need for divided attention during driving in order to strategically evaluate age-related differences in inattentional blindness within a driving context. Thus, in order to ensure that participants were actually performing the task as instructed, and to determine whether there were age-related differences in performing the gap judgment task itself, accuracy scores were calculated and compared between groups. Overall, participants were quite accurate in the gap judgment task ( $82 \%$ overall). In order to determine whether gap judgment accuracy varied as a function of gap size and age, we used a logistic mixed effect model with accuracy as a binary dependent measure (correct vs. incorrect) and gap size (wide vs. narrow), age (younger vs. older), and their corresponding interaction as fixed effects. Whereas there was no effect of gap size on overall accuracy of gap perception judgments, there was an effect of age group with younger adults being more accurate than older adults, $\beta=0.38, S E=0.19, Z=2.06, p=0.039$. This was further qualified by a marginal gap size $\times$ age interaction, $\beta=-0.47, S E=0.26, Z=-1.82, p=0.069$ whereby younger adults were more accurate than older adults in the trials with the wider gap size but not the narrower gap size (Figure 4). Nonetheless, both younger and older adults were overall quite accurate in making the gap judgments ( 87 and $77 \%$, respectively), suggesting that they were able and compliant in performing the gap judgment task.

\section{Inattentional Blindness}

To measure the rate of inattentional blindness, the analysis file was subsetted to include only the four critical trials in which the forced-choice recognition test was administered. Furthermore, to ensure that participants were engaged in the gap judgment task on each critical trial, all trials in which participants made an incorrect gap judgment were excluded (the average rate of inattentional blindness was no different when incorrect gap judgments were included). The rate of inattentional blindness was measured in terms of accuracy (correct selection of target object during the recognition task), with lower accuracy indicating a higher level of inattentional blindness. The model for the analysis included age, animacy, and their interaction as fixed effects.

Results indicated that the only significant effect observed was that of animacy, $\beta=0.83 S E=0.21, Z=3.99, p<0.001$, with better recognition accuracy for animate than inanimate objects for both groups. As illustrated by Figure 5, the differences in detection of animate versus inanimate objects are more pronounced in the younger adults, although this was not statistically significant. We then conducted a follow-up growth curve analysis (Mirman, 2014) to analyze whether inattentional blindness varied across the four critical trials as a function of the order in which they were presented (trial numbers $3,9,12$, and 17). It is, for 


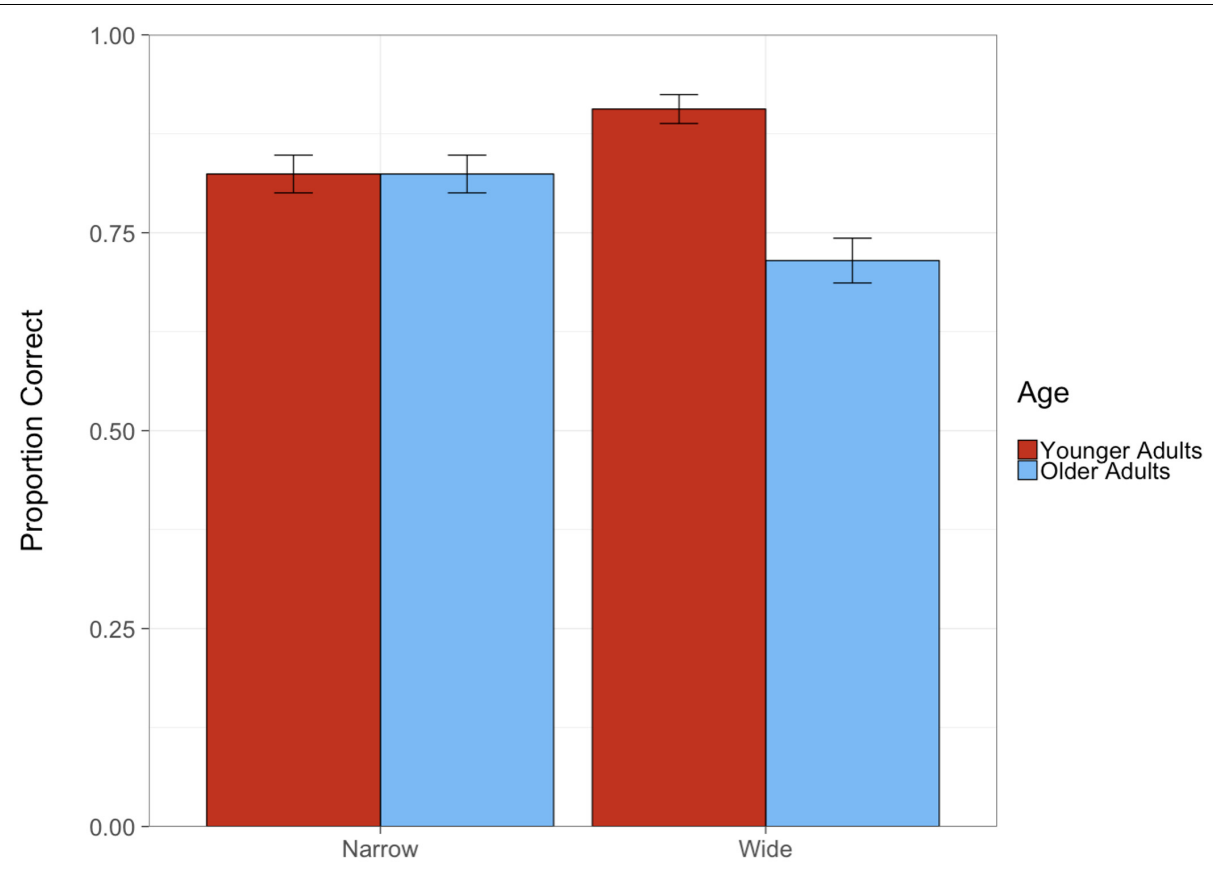

Gap Size

FIGURE 4 | Proportion of correct gap judgments as a function of gap size and age (error bars denote standard error).

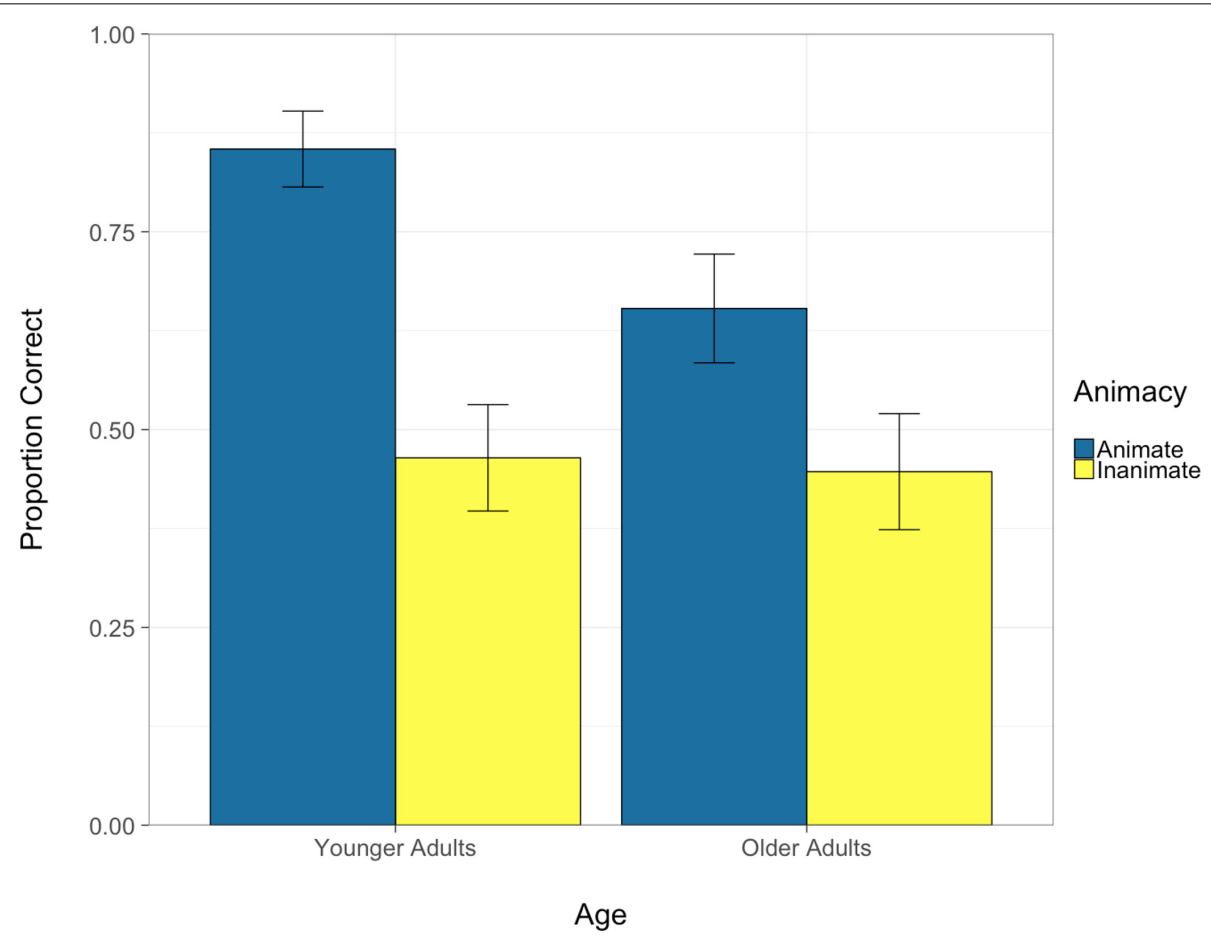

FIGURE 5 | Proportion of correctly identified objects as a function of age and object animacy (error bars denote standard error).

instance, possible that after the first critical trial, participants were primed to attend more to environmental objects than they had been previously, which could then have affected their distribution of attentional resources in later trials. The overall time course of accuracy was modeled with a second-order (quadratic) polynomial and included fixed effects of both age 


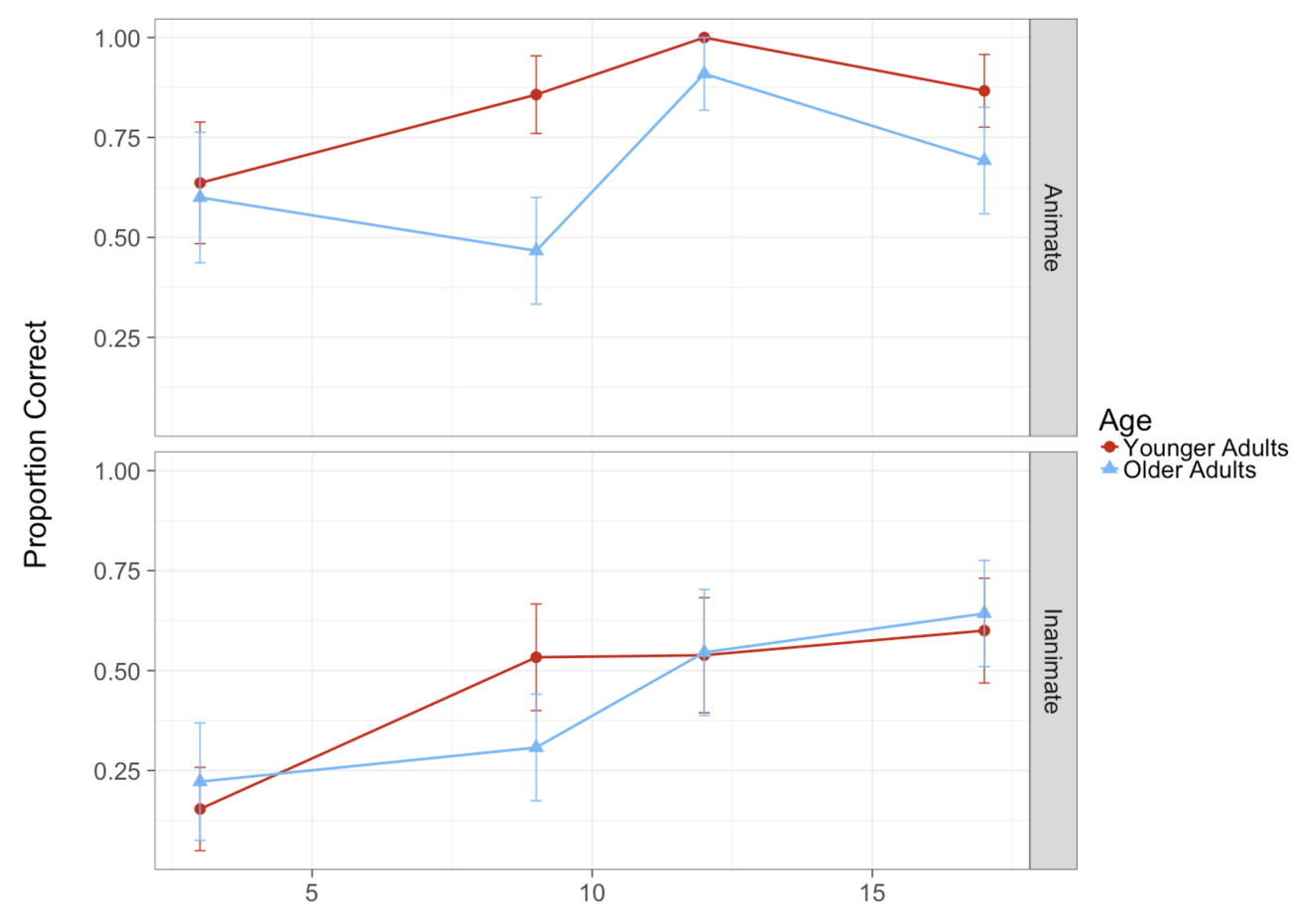

Trial Numbers

FIGURE 6 | Proportion correct across the four critical trials (3, 9, 12, and 17) as a function of age and animacy (error bars denote standard error).

and animacy conditions on all time terms. However, due to limited count of observations, the full model would not converge, thus the random effect structure was simplified to include only participant random effects on all time terms. In addition to the effect of animacy, $\beta=0.95, S E=0.21, Z=4.58, p<0.001$, we also observed a significant effect of age group on the linear time term, $\beta=0.78, S E=0.38, Z=2.04, p=0.042$. As illustrated in Figure 6, this is mainly driven by the performance on the second critical trial (Trial 9), whereby younger adults demonstrate reduced inattentional blindness in the second critical trial compared to older adults who did not show this effect. This pattern of results is evident in both animate and inanimate conditions with differences being more pronounced in the former. We describe the implications of this pattern in greater detail in the section "Discussion."

\section{Incorrect Recognition Trials}

Each response was coded not only in terms of correct and incorrect detection of the critical target, but for the type of incorrect responses, namely whether participants selected the human competitor or a non-human object that never appeared in the scene (e.g., newspaper stand and bicycle). Interestingly, the pattern of results revealed that participants were more likely to pick the non-human object than the human competitor. Furthermore, not only was this pattern of results consistent across both age groups, it was also consistent across trials. In fact, as can be seen in Table 3, it is only the last critical trial in which participants were more likely to incorrectly select the human competitor compared to the non-human object (similar patterns of results are observed after excluding trials with the incorrect gap judgment). We speculate that the reversal of the pattern in the last trial whereby the human competitor was selected more often than the non-human competitor may be due to the overall greater exposure to human characters in the preceding trials.

\section{DISCUSSION}

In the present study, patterns of inattentional blindness were compared between younger and older adults while they performed a simulated driving task. In particular, we examined whether the awareness of roadside objects differed between the two age groups and whether the animacy of the objects affected awareness. Load was introduced by asking participants to make a

TABLE 3 | The number (percentage) of incorrect decisions for human vs. non-human competitor.

\begin{tabular}{lccccc}
\hline & \multicolumn{2}{c}{ Younger adults } & & \multicolumn{2}{c}{ Older adults } \\
\cline { 2 - 3 } \cline { 5 - 6 } Trial numbers & Human & Non-human & & Human & Non-human \\
\hline All trials & $17(35 \%)$ & $31(65 \%)$ & & $23(41 \%)$ & $33(59 \%)$ \\
3 & $6(27 \%)$ & $16(73 \%)$ & & $7(37 \%)$ & $12(63 \%)$ \\
9 & $3(30 \%)$ & $7(70 \%)$ & & $6(33 \%)$ & $12(67 \%)$ \\
12 & $1(14 \%)$ & $6(86 \%)$ & & $3(30 \%)$ & $7(70 \%)$ \\
17 & $7(78 \%)$ & $2(22 \%)$ & & $7(78 \%)$ & $2(22 \%)$
\end{tabular}


perceptual gap judgment about whether they could drive through two rows of parked vehicles. In four critical trials participants were asked to identify roadside objects that differed in terms of their animacy. The results demonstrated that both younger and older adults were significantly more aware of animate compared to inanimate roadside objects, with a trend of this effect being more pronounced in younger compared to older adults. Further, younger adults demonstrated reduced inattentional blindness after the first critical trial, whereas older adults did not show this immediate improvement and continued to exhibit a high rate of inattentional blindness in the second trial. This implies that they did not distribute their attention differentially across the primary driving task and the roadside objects as a function of the prior task demands. Notably, when inattentional blindness was observed (i.e., failure to select the correct human), the erroneous choice was significantly more likely to be the non-human object rather than the other human competitor, for both animate and inanimate critical trials and across both age groups, suggesting that they were truly unaware.

\section{Effects of Age on Inattentional Blindness During Driving}

The previously described phenomenon of inattentional blindness during driving in younger adults (Most and Astur, 2007; Blalock et al., 2014; Murphy and Greene, 2015, 2016, 2017a,b; Ericson et al., 2017) was replicated in the current study and was expanded upon by demonstrating the same phenomenon in older adults. Specifically, participants were unaware of inanimate objects on $56 \%$ of all trials and animate objects on $25 \%$ of all trials (see Table 4). When only considering the very first trial, which is (a) the trial most comparable to other studies of inattentional blindness, which typically test awareness only once, and (b) the only trial preserved against priming or carryover effects, it was observed that participants were unaware of inanimate objects on $82 \%$ of the trials and were unaware of animate objects on $38 \%$ of the trials. Further, when considering the very last trial, when participants had already been asked three previous times to recognize an object present during driving, performance was still not at ceiling levels with $38 \%$ of inattentional blindness observed for inanimate objects and $22 \%$ observed for animate objects. This indicates that when performing a moderately difficult driving task, drivers very often lacked conscious awareness of potentially relevant aspects of their surroundings; particularly when they were probed unexpectedly (first trial), but even when they could

TABLE 4 | The rate of inattentional blindness as a function of age and animacy for each trial.

\begin{tabular}{lccccc}
\hline & \multicolumn{2}{c}{ Younger adults } & & \multicolumn{2}{c}{ Older adults } \\
\cline { 2 - 3 } \cline { 5 - 6 } Trial numbers & Animate & Inanimate & & Animate & Inanimate \\
\hline All trials & $16 \%$ & $54 \%$ & & $33 \%$ & $57 \%$ \\
3 & $36 \%$ & $85 \%$ & & $40 \%$ & $78 \%$ \\
9 & $14 \%$ & $47 \%$ & & $53 \%$ & $69 \%$ \\
12 & $0 \%$ & $46 \%$ & & $9 \%$ & $45 \%$ \\
17 & $13 \%$ & $40 \%$ & & $31 \%$ & $36 \%$
\end{tabular}

anticipate being asked (last trial). This observation was bolstered by the fact that recognition errors were almost twice as likely to be due to selecting a non-human object (e.g., bicycle and newspaper stand) rather than the human competitor, suggesting that it was not just a matter of having difficulty distinguishing subtle human features, but rather a general unawareness.

Interestingly, however, older adults did not demonstrate overall higher or lower rates of inattentional blindness compared to younger adults, counter to initial predictions. This suggests that, within the constraints of this task, there was no evidence to support older adults' reduced awareness of roadside objects due to a generally lower attentional capacity, or an increased awareness of roadside objects due to poorer inhibitory control. There was, however, some indication that older adults did not as rapidly adjust their distribution of attentional resources after learning from previous trial demands. Specifically, whereas younger adults demonstrated significantly reduced inattentional blindness after having already been previously prompted to attend to roadside objects by the recognition task (perhaps priming them to anticipate that they may have to divide their attention in order to recognize future roadside objects), older adults did not. The need for flexible adjustment of task demands could be particularly important in the context of real world driving.

The largely comparable levels of inattentional blindness in younger and older adults observed in this study are different from some prior studies demonstrating higher rates of inattentional blindness in older compared to younger adults in non-driving tasks (e.g., Graham and Burke, 2011). The current results are also different from some driving-context specific studies of hazard detection that have shown lower detection rates in older compared to younger drivers (e.g., Bromberg et al., 2012; Feng et al., 2018; although see Borowsky et al., 2010). However, the results of the current study are consistent with other previous studies reporting measures of awareness as evidenced through explicit detection tasks and actual driving performance metrics under conditions of load (e.g., Strayer and Drews, 2004; Stinchcombe and Gagnon, 2013). For instance, Stinchcombe and Gagnon (2013) reported no age-related differences between middle aged and older drivers for driving performance measures or peripheral detection task accuracy during complex driving tasks known to be associated with real world collisions. Further, Strayer and Drews (2004) reported that while both older and younger adults were negatively affected by talking on a cell phone during simulated driving (e.g., slower reaction times and increased rear-end collisions), there were no age-related differences. Taken together, in the below discussion we consider the parameters that differ across these studies to highlight the potential role that particular factors may play in the observed results including, the nature of the task (e.g., recall vs. recognition vs. driving performance), the magnitude of load (e.g., lower vs. moderate vs. higher perceptual/cognitive load), the nature of the "unexpected" object/feature (e.g., relevance to the primary task), and how these factors may interact with age.

One of the primary differences across studies of inattentional blindness, situational awareness, and hazard detection across driving and non-driving tasks relates to the way that "awareness" is operationalized and measured. For instance, in the current 
study, a post-drive recognition task was used, whereas other studies of inattentional blindness have asked participants to freely recall an object/event (e.g., "did you notice anything different/unusual on the last trial," Graham and Burke, 2011; Murphy and Greene, 2016), and yet others have considered driving performance measures like brake reaction times (e.g., Strayer and Drews, 2004; Ericson et al., 2017). These different task types may be uniquely targeting implicit versus explicit levels of awareness. Therefore, it is possible that older adults may have a reduced conscious awareness of scene/object differences across trials compared to younger adults (e.g., poorer recall accuracy; Graham and Burke, 2011), but they may still have an implicit awareness of having seen that object with comparable accuracy to younger adults (i.e., similar recognition accuracy as was observed in the current study). Indeed, there is significant evidence in the general aging and cognition literature that recall is more significantly affected by older age than is recognition (Craik and McDowd, 1987; Danckert and Craik, 2013) and explicit memory is more significantly affected (or oppositely affected) by older age than implicit memory (La Voie and Light, 1994; Gopie et al., 2011). There are also interesting implications regarding these distinctions when considering how implicit and explicit awareness are associated with actual driving performance measures. It is likely that even without explicit or conscious awareness, implicit detection may result in associated changes in driving performance. This interpretation is consistent with the agreement between comparable performance by older and younger drivers on the recognition-based responses in the current study and the comparable performance of older and younger drivers reported for other driving performance related measures across other studies (e.g., Strayer and Drews, 2004).

Differences across studies could also relate to the various types and levels of perceptual and/or cognitive load that are introduced (Lavie, 2005; Murphy et al., 2016) and the different effects of load on older compared to younger adults. It may be that under low load conditions younger and older drivers perform similarly well and under high load conditions younger and older drivers perform similarly poorly. Therefore, it may be during moderately loaded conditions that age-related effects are best revealed. Given that it is difficult to normalize load across studies, it is possible that the load introduced in the current study was higher or lower than in other previous studies of age-related effects on inattentional blindness, and/or age-related effects of object awareness during driving. It is also possible that the different methods of stimulus presentation could be contributing to differences in age-related effects. For instance, smaller fieldof-view displays and/or video or photo-based stimuli may result in different age-related effects compared to larger field-of-view displays, or immersive simulation systems, as well as where the stimuli appear within these displays (e.g., within or outside of the useful field of view).

\section{Effects of Animacy on Inattentional Blindness During Driving}

In addition to the effects of the context, task, and load on inattentional blindness, the relevance of the unexpected object to the primary task itself may also be a contributing factor. In inattentional blindness studies, the target object of interest is often referred to as "irrelevant" to the main task or "unexpected." The same may not be true in contextualized tasks such as driving where the environmental features and objects can differ and vary dynamically in terms of their relevance (e.g., proximity to roadway, or ability to interfere with the primary driving task) (Pammer and Blink, 2013; Pammer et al., 2015; Topolšek et al., 2016; Murphy and Greene, 2017a). Animacy is a characteristic that is particularly relevant in the context of driving given that it introduces the increased probability that the object could interfere/interact with the driving task. The results of the current study revealed a highly significant effect of animacy, with much higher recognition rates of animate compared to inanimate objects. Importantly, the physical features of the animate and inanimate objects in this study were essentially identical, with the difference being how the object was contextualized (i.e., embedded in an advertisement or not). This effect of animacy was also observed across age groups and across trials and the effect is consistent with past studies involving both non-driving tasks as well as driving relevant scenes (Pammer and Blink, 2013; Calvillo and Jackson, 2014; Pammer et al., 2015; Calvillo and Hawkins, 2016; Topolšek et al., 2016).

Even though there was no significant interaction effect between age group and animacy, it is interesting to note that younger adults demonstrated quite a high rate of awareness for animate objects across trials (84\%) compared to older adults who were relatively poorer $(67 \%)$; which was in contrast to the inanimate trials, for which younger and older adults were much more comparable to each other (46 and 43\%, respectively). This suggests that the influence of animacy on response selection was more pronounced for younger adults than older adults. The implications for this during a real driving context could mean that older adults may not be as strategically attending to potentially relevant environmental information in the same way as younger adults (Bromberg et al., 2012; Horwood and Beanland, 2016; Feng et al., 2018).

\section{Potential Limitations and Future Directions}

Although the current study was targeted at evaluating age-related effects on inattentional blindness during driving, it did not control for between-group differences in terms of lifetime history of driving experience. Whereas it was ensured that all participants had valid driver's licenses and that there were no statistically significant between-group differences in current driving habits (i.e., average $\mathrm{km}$ driven per week), older adults likely had driven for more years total than younger adults. Therefore, greater experience with driving overall may have allowed older adults to use acquired driving skills to compensate for any potential agerelated declines in sensory, motor, or cognitive abilities, resulting in no overall age-related differences on task performance. Yet another possibility is that even though all participants received the same instructions to drive constantly at $80 \mathrm{~km} / \mathrm{h}$, with compliance verified during the practice trials, perhaps during experimental trials older adults modulated their speed differently 

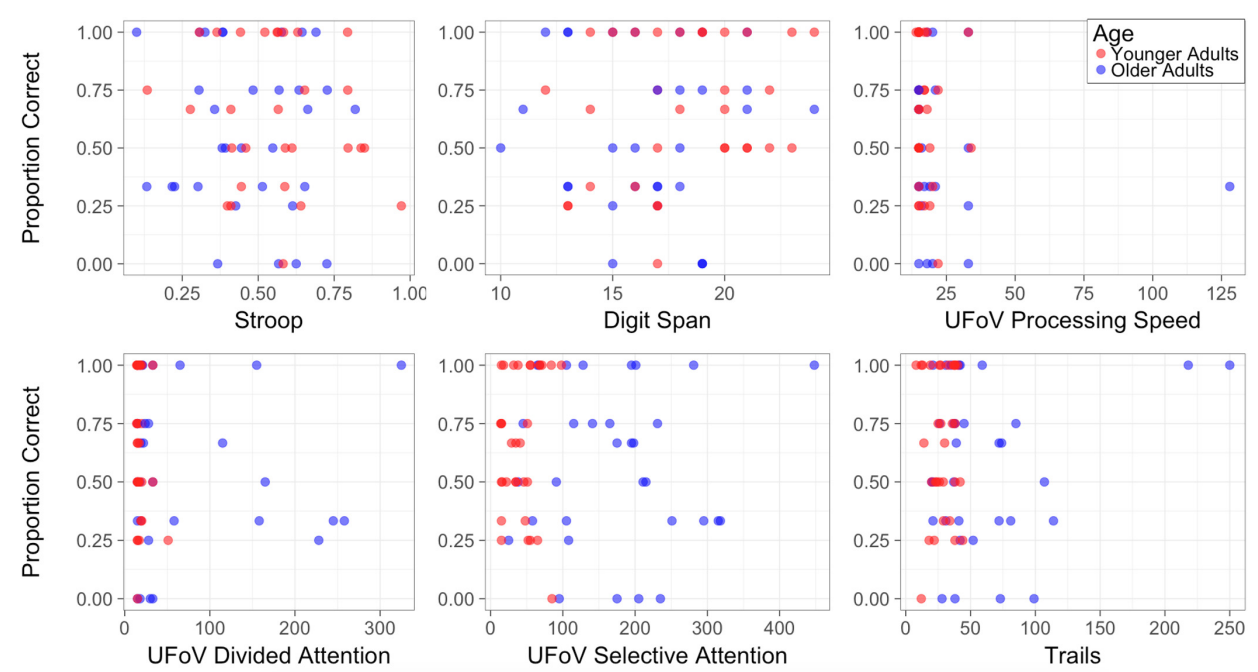

FIGURE 7 | Relation between cognitive assessments and the experimental recognition task performance (Stroop: number of correct words per second from neutral to incongruent condition; Digit Span: correct scores out of 30; UFoV measures are calculated in milliseconds; Trails: the difference in seconds between Trail B-A).

than younger adults. To explore this possibility, we verified the average speed of participants across the four critical trials (from the onset of the sound to the first parked vehicle). We found that younger and older adults were able to maintain the target speed with good accuracy $\left(M_{\text {Older }}=79 \mathrm{~km} / \mathrm{h}\right.$ and $\left.M_{\text {Younger }}=84 \mathrm{~km} / \mathrm{h}\right)$. Nonetheless, it is quite possible that when a speed limit is not strictly enforced, older adults may slow down in order to better manage the multiple tasks of driving (gap judgment and driving maneuvers), while also remaining aware of their surroundings (recognition task performance) (Bromberg et al., 2012). Similarly, even though all participants were asked to drive through the gap when it was wide enough to clear, older adults may have taken a more conservative approach and opted to drive around the vehicles during larger gap sizes than younger adults, even if they perceived it to be wide enough to fit through.

The older adult sample included here may also not be representative of the wider older adult driving population due to the strict eligibility criteria requiring no sensory, motor, or cognitive impairments and requiring an active driving status (licensed and frequent drivers). Indeed, the younger and older adult groups in this study were generally well matched on baseline tests of general functioning. For example, there were no significant between-group differences on tests of working memory (digit span), inhibition (Stroop), and processing speed (UFoV subset). Likewise, there were no observable differences in terms of participants who scored below the cutoff for mild cognitive impairment on the MoCA (see also Rapoport et al., 2013). However, older adults did perform significantly poorer on the Trail making test (visual attention and task switching) and the divided and selective attention subsets of the UFoV test. In order to explore the potential associations between individual participant's scores on the baseline measures and their recognition task performance during the main driving experiment, these data were plotted relative to each other (Figure 7). Visual inspection suggests that, for older adults, faster performance on the UFoV divided and selective attention tasks may be associated with better recognition task performance during driving. However, because of the nature of the binary recognition task measure, analyses to test for statistical associations were not possible. It is, therefore, evident that more studies are required to determine the role of individual differences on inattentional blindness in younger and older adults, particularly in the context of driving. Moreover, although the current sample size was similar to previous studies comparing younger and older drivers (e.g., Strayer and Drews, 2004; Stinchcombe and Gagnon, 2013), it may have lacked the sufficient power to detect more subtle age-related differences.

Because the same characters were presented in the same trial order either as animate or inanimate, there might be concern that the characteristic of the particular object in that trial could have differentially influenced the performance, despite the efforts made to ensure that characters were similar in composition, size, and saliency. In order to examine whether target features could have differentially affected recognition, we compared performance differences across different target types and observed no discernable patterns. For instance, we considered whether the sex of the target person affected recognition performance, but it did not appear to, given that the low performance observed in the second critical trial was for a female target and highest performance in the third critical trial was also a female target. Similarly, the first trial with low performance was a male in a suit, but the last probe trial with perfect performance was also a male in a suit.

Finally, as is the case for all simulator studies, the effects observed here may not generalize completely to real world driving. Particularly relevant here is that the consequence of making a gap judgment error (e.g., driving through a gap that is too small) in the simulator is much more benign than if the same error were made during real on-road driving. This consideration may also be influenced by age, as the consequences 
of a collision for older adults is likely to be much more serious than for younger adults given increases in fragility with age and poorer outcomes associated with injury and recovery (Vichitvanichphong et al., 2015).

\section{CONCLUSION}

Overall, the current results demonstrate that younger and older drivers had similar rates of inattentional blindness when evaluated using a recognition task within a driving paradigm. The most robust factor affecting inattentional blindness was the animacy of the roadside object, with animate objects being recognized significantly more often than inanimate objects. The effects of inattentional blindness were most pronounced on the very first trial, but persisted even after being primed three times prior. While younger adults appeared to distribute their attention more strategically after becoming aware of the potential task of recognizing roadside objects after the first trial, it took more trials for the older adults to redistribute their attention. Factors associated with whether age-related changes influence the rate of inattentional blindness could include the nature of the task/context, the magnitude of perceptual and cognitive load, and the features of the environment to be attended and/or ignored.

\section{ETHICS STATEMENT}

All subjects gave written informed consent in accordance with the Declaration of Helsinki. The protocol was

\section{REFERENCES}

Anderson, J. A., Campbell, K. L., Amer, T., Grady, C. L., and Hasher, L. (2014). Timing is everything: age differences in the cognitive control network are modulated by time of day. Psychol. Aging 29, 648-657. doi: 10.1037/a0037243

Ball, K., and Owsley, C. (1993). The useful field of view test: a new technique for evaluating age-related declines in visual function. J. Am. Optom. Assoc. 64, 71-79.

Bates, D., Maechler, B., Bolker, B., and Walker, S. (2015). Fitting linear mixedeffects models using lme4. J. Stat. Softw. 67, 1-48. doi: 10.18637/jss.v067.i01

Blalock, L. D., Sawyer, B. D., Kiken, A., Gutzwiller, R. S., McGill, C. L., and Clegg, B. A. (2014). Cognitive load while driving impairs memory of moving but not stationary elements within the environment. J. Appl. Res. Mem. Cogn. 3, 95-100. doi: 10.1016/j.jarmac.2014.04.006

Borowsky, A., Shinar, D., and Oron-Gilad, T. (2010). Age, skill, and hazard perception in driving. Accid. Anal. Prev. 42, 1240-1249. doi: 10.1016/j.aap.2010. 02.001

Bromberg, S., Oron-Gilad, T., Ronen, A., Borowsky, A., and Parmet, Y. (2012). The perception of pedestrians from the perspective of elderly experienced and experienced drivers. Accid. Anal. Prev. 44, 48-55. doi: 10.1016/j.aap.2010. 12.028

Caird, J. K., Simmons, S. M., Wiley, K., Johnston, K. A., and Horrey, W. J. (2018). Does talking on a cell phone, with a passenger, or dialing affect driving performance? An updated systematic review and meta-analysis of experimental studies. Hum. Factors 60, 101-133. doi: 10.1177/0018720817748145

Calvillo, D. P., and Hawkins, W. C. (2016). Animate objects are detected more frequently than inanimate objects in inattentional blindness tasks independently of threat. J. Gen. Psychol. 143, 101-115. doi: 10.1080/00221309. 2016.1163249 approved by the University Health Network's Research Ethics Board (REB 17-5596).

\section{AUTHOR CONTRIBUTIONS}

RS and JC conceived the study. RS and KB collected the data. $\mathrm{RS}$, JC, and $\mathrm{KB}$ contributed to the analyses and to the writing of the manuscript.

\section{FUNDING}

This study was supported by Natural Sciences and Engineering Research Council of Canada Discovery Grant awarded to JC (RGPIN-2015-06619) and Alzheimer's Association International New Investigator Grant awarded to JC (2015-NIRG-341026).

\section{ACKNOWLEDGMENTS}

We would like to thank Bruce Haycock for design consultation, programming, and troubleshooting. We also thank Ali Seyed Norani and Niroshica Mohanathas for assistance in data collection, Susan Gorski, Roger Montgomery, Robert Shewaga, Barry Westhead, and Zayne Thawer for technical support, Behrang Keshavarz for consultation in regards to simulator sickness and Craig Chambers for his valuable feedback.

Calvillo, D. P., and Jackson, R. E. (2014). Animacy, perceptual load, and inattentional blindness. Psychon. Bull. Rev. 21, 670-675. doi: 10.3758/s13423013-0543-8

Cantin, V., Lavallière, M., Simoneau, M., and Teasdale, N. (2009). Mental workload when driving in a simulator: effects of age and driving complexity. Accid. Anal. Prev. 41, 763-771. doi: 10.1016/j.aap.2009.03.019

Craik, F. I., and McDowd, J. M. (1987). Age differences in recall and recognition. J. Exp. Psychol. Learn. Mem. Cogn. 13, 474-479. doi: 10.1037/0278-7393.13. 3.474

Cuenen, A., Jongen, E. M., Brijs, T., Brijs, K., Lutin, M., Van Vlierden, K., et al. (2015). Does attention capacity moderate the effect of driver distraction in older drivers? Accid. Anal. Prev. 77, 12-20. doi: 10.1016/j.aap.2015.01.011

Danckert, S. L., and Craik, F. I. (2013). Does aging affect recall more than recognition memory? Psychol. Aging 28, 902-909. doi: 10.1037/a0033263

Donmez, B., and Liu, Z. (2015). Associations of distraction involvement and age with driver injury severities. J. Saf. Res. 52, 23-28. doi: 10.1016/j.jsr.2014.12.001

Ebnali, M., Ahmadnezhad, P., Shateri, A., Mazloumi, A., Heidari, M. E., and Nazeri, A. R. (2016). The effects of cognitively demanding dual-task driving condition on elderly people's driving performance, Real driving monitoring. Accid. Anal. Prev. 94, 198-206. doi: 10.1016/j.aap.2016.05.016

Ericson, J. M., Parr, S. A., Beck, M. R., and Wolshon, B. (2017). Compensating for failed attention while driving. Transp. Res. F Traffic Psychol. Behav. 45, 65-74. doi: 10.1016/j.trf.2016.11.015

Feng, J., Choi, H., Craik, F. I., Levine, B., Moreno, S., Naglie, G., et al. (2018). Adaptive response criteria in road hazard detection among older drivers. Traffic Inj. Prev. 19, 141-146. doi: 10.1080/15389588.2017.1373190

Ferris, F. L. III, Kassoff, A., Bresnick, G. H., and Bailey, I. (1982). New visual acuity charts for clinical research. Am. J. Ophthalmol. 94, 91-96. doi: 10.1016/00029394(82)90197-0 
Golding, J. F. (2006). Predicting individual differences in motion sickness susceptibility by questionnaire. Pers. Individ. Dif. 41, 237-248. doi: 10.1016/j. paid.2006.01.012

Gopie, N., Craik, F. I., and Hasher, L. (2011). A double dissociation of implicit and explicit memory in younger and older adults. Psychol. Sci. 22, 634-640. doi: $10.1177 / 0956797611403321$

Graham, E. R., and Burke, D. M. (2011). Aging increases inattentional blindness to the gorilla in our midst. Psychol. Aging 26, 162-166. doi: 10.1037/a0020647

Hasher, L., and Zacks, R. T. (1988). "Working memory, comprehension, and aging: a review and a new view," in Psychology of Learning and Motivation, Vol. 22, ed. G. H. Bower, (New York, NY: Academic Press), 193-225.

Horrey, W. J., and Wickens, C. D. (2006). Examining the impact of cell phone conversations on driving using meta-analytic techniques. Hum. Factors 48, 196-205. doi: 10.1518/001872006776412135

Horwood, S., and Beanland, V. (2016). Inattentional blindness in older adults: effects of attentional set and to-be-ignored distractors. Attent. Percept. Psychophys. 78, 818-828. doi: 10.3758/s13414-015-1057-4

International Council of Ophthalmology (2002). Visual Standards Aspects and Ranges of Vision Loss with Emphasis on Population Surveys. Available at: www.icoph.org/pdf/visualstandardsreport.pdf (accessed November 3, 2018).

Jackson, L., and Cracknell, R. (2018). Road Accident Casualties in Britain and the World. Available at: https://researchbriefings.parliament.uk/ResearchBriefing/ Summary/CBP-7615 (accessed April 23, 2018).

Kass, S. J., Cole, K. S., and Stanny, C. J. (2007). Effects of distraction and experience on situation awareness and simulated driving. Transp. Res. F Traffic Psychol. Behav. 10, 321-329. doi: 10.1016/j.trf.2006.12.002

Keshavarz, B., and Hecht, H. (2011). Validating an efficient method to quantify motion sickness. Hum. Factors 53, 415-426. doi: 10.1177/0018720811403736

Kreitz, C., Furley, P., Memmert, D., and Simons, D. J. (2016). The influence of attention set, working memory capacity, and expectations on inattentional blindness. Perception 45, 386-399. doi: 10.1177/0301006615614465

Kuznetsova, A., Brockhoff, P. B., and Christensen, R. H. B. (2017). lmerTest package: tests in linear mixed effects models. J. Stat. Softw. 82, 1-26. doi: 10. 18637/jss.v082.i13

La Voie, D., and Light, L. L. (1994). Adult age differences in repetition priming: a meta-analysis. Psychol. Aging 9, 539-553. doi: 10.1037/0882-7974.9.4.539

Lavie, N. (2005). Distracted and confused?: Selective attention under load. Trends Cogn. Sci. 9, 75-82. doi: 10.1016/j.tics.2004.12.004

Lavie, N., Ro, T., and Russell, C. (2003). The role of perceptual load in processing distractor faces. Psychol. Sci. 14, 510-515. doi: 10.1111/1467-9280.03453

Liu, H. (2018). Age-related effects of stimulus type and congruency on inattentional blindness. Front. Psychol. 9:794. doi: 10.3389/fpsyg.2018.00794

Lustig, C., Hasher, L., and Zacks, R. T. (2007). Inhibitory deficit theory: recent developments in a "new view". Inhib. Cogn. 17, 145-162. doi: 10.1037/ 11587-008

Mack, A., and Rock, I. (1998). Inattentional Blindness. Cambridge, MA: MIT Press. doi: 10.7551/mitpress/3707.001.0001

Marciano, H., and Yeshurun, Y. (2012). Perceptual load in central and peripheral regions and its effects on driving performance: advertizing billboards. Work 41, 3181-3188. doi: 10.3233/WOR-2012-0580-3181

Marciano, H., and Yeshurun, Y. (2015). Perceptual load in different regions of the visual scene and its Relevance for driving. Hum. Factors 54, 701-716. doi: 10.1177/0018720814556309

McDowd, J. M., and Craik, F. I. (1988). Effects of aging and task difficulty on divided attention performance. J. Exp. Psychol. Hum. Percept. Perform. 14, 267-280. doi: 10.1037/0096-1523.14.2.267

Michaels, J., Chaumillon, R., Nguyen-Tri, D., Watanabe, D., Hirsch, P., Bellavance, F., et al. (2017). Driving simulator scenarios and measures to faithfully evaluate risky driving behavior: a comparative study of different driver age groups. PLoS One 12:e0185909. doi: 10.1371/journal.pone.0185909

Mirman. (2014). Growth Curve Analysis and Visualization Using R. Boca Raton, FL: Chapman and Hall.

Most, S. B., and Astur, R. S. (2007). Feature-based attentional set as a cause of traffic accidents. Vis. Cogn. 15, 125-132. doi: 10.1080/13506280600959316

Murphy, G., and Greene, C. M. (2015). High perceptual load causes inattentional blindness and deafness in drivers. Vis. Cogn. 23, 810-814. doi: 10.1080/ 13506285.2015.1093245
Murphy, G., and Greene, C. M. (2016). Perceptual load induces inattentional blindness in drivers. Appl. Cogn. Psychol. 30, 479-483. doi: 10.1002/acp.3216

Murphy, G., and Greene, C. M. (2017a). Load theory behind the wheel; perceptual and cognitive load effects. Can. J. Exp. Psychol. 71, 191-202. doi: 10.1037/ cep0000107

Murphy, G., and Greene, C. M. (2017b). The elephant in the road: auditory perceptual load affects driver perception and awareness. Appl. Cogn. Psychol. 31, 258-263. doi: 10.1002/acp.3311

Murphy, G., Groeger, J. A., and Greene, C. M. (2016). Twenty years of load theory - Where are we now, and where should we go next? Psychon. Bull. Rev. 23, 1316-1340. doi: 10.3758/s13423-015-0982-5

Nasreddine, Z. S., Phillips, N. A., Bédirian, V., Charbonneau, S., Whitehead, V., Collin, I., et al. (2005). The Montreal Cognitive Assessment, MoCA: a brief screening tool for mild cognitive impairment. J. Am. Geriatr. Soc. 53, 695-699. doi: 10.1111/j.1532-5415.2005.53221.x

Owsley, C., Stalvey, B., Wells, J., and Sloane, M. E. (1999). Older drivers and cataract: driving habits and crash risk. J. Gerontol. Med. Sci. 54A, M203-M211. doi: 10.1093/gerona/54.4.m203

Pammer, K., Bairnsfather, J., Burns, J., and Hellsing, A. (2015). Not all hazards are created equal: the significance of hazards in inattentional blindness for static driving scenes. Appl. Cogn. Psychol. 29, 782-788. doi: 10.1002/acp.3153

Pammer, K., and Blink, C. (2013). Attentional differences in driving judgments for country and city scenes: semantic congruency in inattentional blindness. Accid. Anal. Prev. 50, 955-963. doi: 10.1016/j.aap.2012.07.026

R Core Team (2017). R: A Language and Environment for Statistical Computing. Vienna: R Foundation for Statistical Computing.

Rapoport, M. J., Naglie, G., Weegar, K., Myers, A., Cameron, D., Crizzle, A., et al. (2013). The relationship between cognitive performance, perceptions of driving comfort and abilities, and self-reported driving restrictions among healthy older drivers. Accid. Anal. Prev. 61, 288-295. doi: 10.1016/j.aap.2013.03.030

Reitan, R. M. (1955). The relation of the Trail Making Test to organic brain damage. J. Consult. Psychol. 19, 393-394. doi: 10.1037/h0044509

Road Safety Canada (2011). Road Safety in Canada Report. Ottawa: The Public Health Agency of Canada.

Shinar, D., Tractinsky, N., and Compton, R. (2005). Effects of practice, age, and task demands, on interference from a phone task while driving. Accid. Anal. Prev. 37, 315-326. doi: 10.1016/j.aap.2004.09.007

Simons, D. J., and Chabris, C. F. (1999). Gorillas in our midst: sustained inattentional blindness for dynamic events. Perception 28, 1059-1074. doi: 10. 1068/p281059

Smahel, T., Smiley, A., and Donderi, D. (2008). "The effects of cellular phone use on novice and experienced driver performance: an on-road study," in Proceedings of the Human Factors and Ergonomics Society Annual Meeting, Vol. 52, (Thousand Oaks, CA: Sage Publications), 1910-1914. doi: 10.1177/ 154193120805202317

Stinchcombe, A., and Gagnon, S. (2013). Aging and driving in a complex world: exploring age differences in attentional demand while driving. Transp. Res. F Traffic Psychol. Behav. 17, 125-133. doi: 10.1016/j.trf.2012.11.002

Stothart, C., Boot, W., and Simons, D. (2015). Using Mechanical Turk to assess the effects of age and spatial proximity on inattentional blindness. Collabra 1, 1-7. doi: $10.1525 /$ collabra.26

Stothart, C., Boot, W. R., Simons, D., Charness, N., and Wright, T. (2016). “Age effects on inattentional blindness: implications for driving," in Human Aspects of IT for the Aged Population. Healthy and Active Aging, eds J. Zhou and G. Salvendy (Cham: Springer), doi: 10.1007/978-3-319-39949-2_42

Strayer, D. L., Cooper, J. M., Turrill, J., Coleman, J., Medeiros-Ward, N., and Biondi, F. (2013). Measuring Cognitive Distraction in the Automobile. Washington, DC: AAA Foundation for Traffic Safety.

Strayer, D. L., and Drews, F. A. (2004). Profiles in driver distraction: effects of cell phone conversations on younger and older drivers. Hum. Factors 46, 640-649. doi: 10.1518/hfes.46.4.640.56806

Strayer, D. L., Drews, F. A., and Johnston, W. A. (2003). Cell phone-induced failures of visual attention during simulated driving. J. Exp. Psychol. Appl. 9, 23-32. doi: 10.1037/1076-898x.9.1.23

Strayer, D. L., and Johnston, W. A. (2001). Driven to distraction: dual-task studies of simulated driving and conversing on a cellular telephone. Psychol. Sci. 12, 462-466. doi: 10.1111/1467-9280.00386 
Stroop, J. R. (1935). Studies of interference in serial verbal reactions. J. Exp. Psychol. 18, 643-662. doi: 10.1037/h0054651

Svetina, M. (2016). The reaction times of drivers aged 20 to 80 during a divided attention driving. Traffic Inj. Prev. 17, 810-814. doi: 10.1080/15389588.2016. 1157590

The MathWorks Inc. (2015). MATLAB and Statistics Toolbox Release 20156. Natick, MA: United States.

Topolšek, D., Areh, I., and Cvahte, T. (2016). Examination of driver detection of roadside traffic signs and advertisements using eye tracking. Transp. Res. $F$ Traffic Psychol. Behav. 43, 212-224. doi: 10.1016/j.trf.2016.10.002

Transport Canada (2014). Canadian Motor Vehicle Traffic Collision Statistics. Available at: https://www.tc.gc.ca/eng/motorvehiclesafety/resourcesresearchstats-menu-847.htm (accessed May 22, 2017).

Vichitvanichphong, S., Talaei-Khoei, A., Kerr, D., and Ghapanchi, A. H. (2015). What does happen to our driving when we get older? Transp. Rev. 35, 56-81. doi: 10.1080/01441647.2014.997819
Wechsler, D. (1997). Wechsler Adult Intelligence Scale, 3rd Edn. San Antonio, TX: The Psychological Corporation.

Wechsler, K., Drescher, U., Janouch, C., Haeger, M., Voelcker-Rehage, C., and Bock, O. (2018). Multitasking during simulated car driving: a comparison of young and older persons. Front. Psychol. 9:910. doi: 10.3389/fpsyg.2018.00910

Conflict of Interest Statement: The authors declare that the research was conducted in the absence of any commercial or financial relationships that could be construed as a potential conflict of interest.

Copyright (c) 2019 Saryazdi, Bak and Campos. This is an open-access article distributed under the terms of the Creative Commons Attribution License (CC BY). The use, distribution or reproduction in other forums is permitted, provided the original author(s) and the copyright owner(s) are credited and that the original publication in this journal is cited, in accordance with accepted academic practice. No use, distribution or reproduction is permitted which does not comply with these terms. 